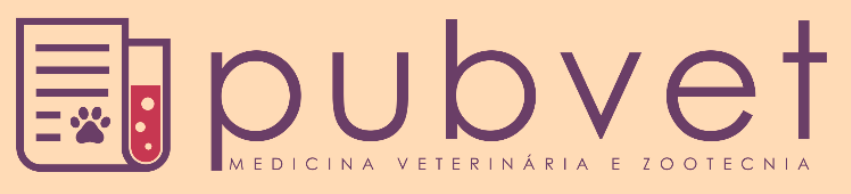

https://doi.org/10.31533/pubvet.v15n01a722.1-8

\title{
Recomendações de granulometria para rações de suínos: Revisão
}

\author{
Mariane Zabotto Evangelista $^{1 *} \bullet$, Cynthia Pieri Zeferino ${ }^{2} \bullet$ (D), Kathery Brennecke ${ }^{3} \bullet$ \\ ${ }^{I}$ Discente no curso de Mestrado Profissional em Produção Animal, Universidade Brasil. Descalvado - SP, Brasil. \\ ${ }^{2}$ Orientadora, docente no curso de Mestrado Profissional em Produção Animal, Universidade Brasil. Descalvado - SP, Brasil. \\ ${ }^{3}$ Docente no curso de Mestrado Profissional em Produção Animal, Universidade Brasil. Descalvado - SP, Brasil. \\ * Autor para correspondência, E-mail: marianezabotto.mba@gmail.com
}

Resumo. A suinocultura se constitui em atividade relevante à economia brasileira. A alimentação representa alto custo na produção animal, deste modo, a forma física dos grãos, em particular o tamanho das partículas dos ingredientes ou a granulometria utilizada nas rações de suínos pode influenciar a qualidade das rações, o que reflete no desempenho, e consequentemente, na produtividade das granjas, além do custo de produção e o nível de poluição ambiental em função da produção de dejetos. Esta revisão tem como objetivo realizar um levantamento com base na literatura científica acerca das diferentes recomendações de granulometria para as rações fornecidas aos suínos, durante a fase de engorda. Conclui-se que para a formulação de ração, recomenda-se a escolha do tamanho correto dos grãos, considerando os objetivos relacionados ao desempenho e saúde dos animais, à digestibilidade dos nutrientes, ao potencial de excreção de poluentes e ao custo de produção.

Palavras-chave: desempenho, diâmetro geométrico médio, moagem da ração, suinocultura, tamanho de partículas

\section{Granulometry recommendation for pig diets: Review}

Abstract. Pig farming is an important activity for Brazilian economy. Feeding represent high cost in animal production, then, physic shape of grains, in main the particle size of feed used in the swine rations can be influence rations quality, that to reflect in the performance and, as a result, in the productivity in the farms, besides production cost and the level of environmental pollution caused by waste production. This revision has like goal to do a data survey based on scientific literature about different recommendations of particle size for rations provided to swine during growing phase. It was concluded that for the feed formulation, the correct choice of grains size is recommended, considering the goals about animal performance and health, nutrients digestibility, poluents excretion potential and production cost.

Keywords: performance, average geometric diameter, feed milling, pig farming, particle size

\section{Recomendaciones de tamaño de partícula para alimentación de cerdos: Revisión}

Resumen. La cría de cerdos es una actividad relevante para la economía brasileña. La alimentación representa un alto costo en la producción animal, por lo tanto, la forma física de los granos, en particular el tamaño de partícula de los ingredientes o la granulometría utilizada en la alimentación de cerdos puede influir en la calidad de la alimentación, lo que se refleja en el rendimiento y, en consecuencia, en la productividad de las granjas, además del costo de producción y el nivel de contaminación ambiental debido a la producción de 
residuos. Esta revisión tiene como objetivo llevar a cabo una encuesta basada en la literatura científica sobre las diferentes recomendaciones de granulometría para los alimentos proporcionados a los cerdos, durante la fase de engorde. Se concluye que para la formulación de alimento, se recomienda elegir el tamaño de grano correcto, considerando los objetivos relacionados con el rendimiento y salud de los animales, digestibilidad de nutrientes, el potencial de excreción de contaminantes y el costo de producción.

Palabras clave: rendimiento, diámetro geométrico promedio, molienda de piensos, cría de cerdos, tamaño de partícula

\section{Introdução}

A suinocultura se constitui em atividade relevante à economia brasileira. Em 2019, o país ocupou a posição de quarto maior produtor de carne suína, com 3.975.000 ton., sendo os três maiores produtores, respectivamente, China (42.550.000 ton.), União Europeia (23.935.000 ton.) e Estados Unidos (12.542.000 ton.). Além disto, o Brasil se posicionou como quarto maior exportador de carne suína, com volume de 861.000 ton., sendo os maiores exportadores, respectivamente, União Europeia (3.551.000 ton.), Estados Unidos (2.867.000 ton.) e Canadá (1.284.000 ton.) (FAPRI, 2020).

No Brasil, em 2018, o consumo interno per capita foi de15 $\mathrm{kg}$ de carne suína e a atividade foi afetada pelo alto custo de produção, devido ao aumento dos preços dos principais insumos para as rações. Entretanto, em 2020 espera-se melhor resposta, pois, de acordo com estimativas a demanda mundial per capita por proteína animal, incluindo a carne suína, deve ser de aproximadamente $83 \mathrm{~kg}$ nos países desenvolvidos, $60 \mathrm{~kg}$ na China e $59 \mathrm{~kg}$ nos países da América Latina (ANUALPEC, 2020; Martins et al., 2019).

Dentre os custos na produção animal, a alimentação responde por $76 \%$, em média (Pandorfi et al., 2012; Talamini \& Santos Filho, 2017). O setor de suinocultura utiliza subprodutos da agroindústria para redução destes custos, entretanto, ainda demanda mais estratégias para a otimização dos insumos. Desta forma, o que se espera dos programas nutricionais é a redução de perdas e o máximo aproveitamento dos nutrientes fornecidos aos animais.

Sabe-se que, junto aos vários processos na fabricação de rações, o tamanho das partículas determina as reações físico-químicas dos nutrientes, as propriedades da superfície das partículas, a estrutura final e o estado de higiene do produto final (Kiarie \& Mills, 2019). Assim, a forma física dos grãos utilizados nas rações de suínos pode influenciar o desempenho e, consequentemente, a produtividade das granjas, além dos custos de produção e o nível de poluição ambiental em função da produção de dejetos.

Esta revisão tem como objetivo realizar um levantamento com base na literatura científica acerca das diferentes recomendações de granulometria para as rações fornecidas aos suínos, durante a fase de engorda. Desta forma, foram apresentados estudos que destacam a influência da granulometria de ingredientes na qualidade da ração, desempenho, saúde intestinal, digestibilidade de nutrientes e excreção de poluentes.

\section{Granulometria: Definição e importância}

A qualidade das rações implica em cuidados ao longo de todo o processo, ou seja, na seleção de fornecedores e nas etapas de recebimento, estocagem, secagem, limpeza, moagem, mistura, peletização, pesagens e empacotamento, além do transporte (Bellaver, 2001), pois erros em uma ou mais etapas podem resultar em prejuízo econômico expressivo, já que a alimentação corresponde à maior parcela dos custos da produção de suínos.

Em geral, a primeira parte na fabricação é a pesagem das matérias-primas. Nesta etapa, as matériasprimas de maior quantidade indicadas na formulação são moídas e pesadas em balança e os ingredientes de menor quantidade, geralmente comprados em sacos, são pesados manualmente. A etapa seguinte à pesagem é a mistura dos ingredientes no misturador, seguida do descarregamento, o qual pode encaminhar o material para o processo de peletização ou para o uso final como ração farelada ou úmida na produção de suínos (Bünzen et al., 2008). 
O controle do processo de moagem durante a fabricação de ração é fundamental, pois está diretamente ligado à eficiência na gestão dos custos, ao desempenho e produtividade do animal, à saúde do trato gastrointestinal (Kiarie \& Mills, 2019) e possivelmente, ao nível de poluição ambiental através dos dejetos. Para Bellaver (2001), a moagem é uma das etapas "coração" de uma fábrica de ração, sendo que a consistência deste processo causa grande impacto na qualidade final dos produtos. A moagem consiste em triturar os ingredientes maiores (grãos) e de maior concentração em partículas menores, para que sejam facilmente incorporados aos micronutrientes, de acordo com as concentrações previstas nas fórmulas de ração. É, portanto, o processo onde os ingredientes são reduzidos em seu tamanho pela força do impacto, corte ou atrito. Desta forma, estes ingredientes podem seguir para as etapas posteriores do processo de fabricação para, ao final, estarem bem distribuídos na mistura final, e assim, serem aceitos e consumidos pelos suínos. Este processo é realizado por moinhos que submetem o ingrediente à quebra e peneiramento, onde a granulometria final é determinada (Bellaver, 2001). Desta forma, a granulometria torna-se importante para a qualidade das rações, sendo um dos principais pontos a serem controlados nas fábricas.

A granulometria é um método de análise que classifica as partículas de uma amostra por tamanho e mensura as frações destas (Zanotto et al., 1999), também pode ser definida como um processo que caracteriza a dimensão das partículas (Zanotto \& Bellaver, 1996). Portanto, é a medida dos grãos maiores (milho e soja) em milímetros $(\mathrm{mm})$ ou micrômetros $(\mu \mathrm{m})$ que passam pelo processo de moagem antes de serem incorporados às rações, para posterior mistura com os ingredientes porosos.

De forma tradicional, a granulometria é calculada com base no diâmetro dos furos das peneiras dos moinhos ou, mais precisamente, pela determinação do tamanho das partículas através do diâmetro geométrico médio (DGM) e pela amplitude das partículas através do desvio padrão geométrico (DPG) que podem ser obtidos através do envio de amostras do produto triturado à laboratório especializado (Penz \& Magro, 1998). Atualmente, o cálculo da granulometria está mais fácil e acessível ao suinocultor com a oferta de softwares no mercado, como o Granucalc ${ }^{\circledR}$, desenvolvido pela EMBRAPA e lançado em 2012.

Segundo estudos, a granulometria varia de acordo com a espécie animal (Penz \& Magro, 1998), além do sexo e da fase de desenvolvimento, conforme a evolução da fisiologia digestiva e a variação da exigência nutricional no decorrer da vida (Healy et al., 1994; Wondra et al., 1995). Inúmeros estudos também apontam para os efeitos do tamanho das partículas dos grãos nas rações de suínos que, combinados ou não com outros fatores, influenciam a uniformidade da ração, o valor nutricional dos ingredientes, o desempenho e o aparecimento de lesões de ulceração nos animais, os custos de produção, além da digestibilidade e da taxa de excreção de poluentes.

\section{Efeitos da granulometria sobre a qualidade da ração}

Amornthewaphat et al. (1998) avaliaram o efeito do tamanho das partículas e tempo de mistura da ração e relataram que as partículas finas melhoraram a uniformidade, enquanto que as grossas resultaram em coeficiente de variação $(\mathrm{CV})$ maior e necessitaram de mais tempo de moagem para alcançar a uniformidade. Segundo os autores, DGM's entre 400 e $600 \mu \mathrm{m}$ resultaram em CV de 15 e 20\%, respectivamente, em 15 segundos de moagem, enquanto para 800 e $1200 \mu \mathrm{m}$ foram necessários entre 25 a 30 segundos. Concluiu-se, então, que as partículas finas melhoraram a uniformidade da ração, enquanto que as grossas apresentaram maior CV.

\section{Efeitos da granulometria sobre o desempenho e a saúde dos suínos}

Leitões recém desmamados passam a consumir proteínas vegetais menos digestíveis em substituição à caseína, proveniente do leite da fêmea suína. Assim, rações iniciais devem ser bem estruturadas, a fim de facilitar a transição da alimentação líquida para a sólida, sem prejudicar a saúde intestinal. Isto porque um organismo sem níveis satisfatórios de amilase e alimentado de forma inadequada apresenta redução na digestibilidade, onde as partículas de alimentos não digeridos no lúmen intestinal se tornam substrato para a proliferação bacteriana indesejada. Tais bactérias causam doenças e, consequentemente, diarreia, à qual interrompe a absorção e a secreção das células intestinais e prejudica a motilidade, resultando em irritação e inflamação do trato gastrointestinal (Oliveira et al., 2005). 
Entre 14 e 21 dias de vida, os leitões não possuem os sistemas imune e digestório completamente desenvolvidos (Zanotto et al., 1998). A partir dos 28 dias, os leitões começam a produzir níveis satisfatórios de amilase, mas ainda exigem maiores cuidados na alimentação. Assim, com o processamento correto do milho e seus derivados, as rações apresentam composição e forma ideal, além do consumo ideal pelo animal, o que contribui para a melhora da digestibilidade, evita o surgimento de diarreias e controla as enfermidades entéricas (Oliveira et al., 2005).

Kim et al. (2002) avaliaram os efeitos da redução do tamanho dos grãos de milho de 1.000 para 500 $\mu \mathrm{m}$ em dietas peletizadas simples (à base de milho e soja) e complexas (à base de soro de leite, lactose, plasma suíno, trigo e sangue) para suínos em creche. Para ambas as dietas, os animais que consumiram ração com grãos de $500 \mu \mathrm{m}$ apresentaram tendência de maior ganho de peso diário e melhora de $31 \%$ na conversão alimentar em relação aos suínos que receberam ração com $1.000 \mu \mathrm{m}$. Contudo, os animais que consumiram dietas complexas à $1.000 \mu \mathrm{m}$ apresentaram melhor desempenho .Ao final do experimento, os suínos alimentados com dieta complexa apresentaram incremento de $10 \%$ no ganho de peso diário, entretanto, piora de 5\% na taxa de conversão alimentar, sendo importante, em função disto, questionar o custo adicional para se produzir dieta complexa, caso não haja atenção para o tamanho das partículas.

De acordo com a literatura, os maiores problemas relacionados à granulometria ocorrem na etapa de creche, durante o desmame. É importante destacar que isto ocorre pois os suínos em crescimento e terminação possuem o sistema digestivo preparado para a digestão de variados ingredientes e formas físicas da ração. Há presença, em níveis satisfatórios, de amilase, pepsina e secreções do intestino delgado: sucos pancreático, duodenal, entérico e bile (Silva et al., 2006).

Ao avaliar o efeito da granulometria do milho moído $(320$ e $650 \mu \mathrm{m})$ em dietas farelada e peletizada para suínos em crescimento, De Jong et al. (2012) relataram que a redução do tamanho dos grãos (320 $\mu \mathrm{m})$ não afetou o ganho de peso diário e o consumo de ração, entretanto, melhorou a conversão alimentar e a eficiência calórica, diminuiu o custo da alimentação por $\mathrm{kg}$ e aumentou a receita. Os autores também constataram que a dieta farelada apresentou redução de ganho de peso diário, de peso final e de peso da carcaça quente e, em contrapartida, que a dieta peletizada, apesar de diminuir a receita, reduziu o custo da alimentação por kg e melhorou a resposta de desempenho dos suínos.

Estudos comprovam que a granulometria da ração pode estar associada à ocorrência de úlcera, doença caracterizada pela inflamação epitelial no quadrilátero esofágico do estômago do suíno (região aglandular), à qual promove eventos morfo patológicos graves como: paraqueratose, hiperqueratose, erosões e ulceração. Desta forma, partículas muito finas resultam em maior consumo de água e de ração, contribuindo para a formação de bolos alimentares maiores e conteúdo estomacal mais fluído, os quais diminuem a taxa de passagem da digesta, estimulam a secreção de suco gástrico (reduzem o $\mathrm{pH}$ ) e aumentam a atividade da pepsina (Hedde et al., 1985). $\mathrm{O} \mathrm{pH}$ de dietas com granulometria fina é abaixo de 3,4, sendo ideal o $\mathrm{pH}$ encontrado em dietas com granulometria grossa, que deve ser maior que 4,7 (Penz \& Magro, 1998).

Morel \& Cottam (2007) avaliaram o efeito dos diferentes tamanhos de grãos de cevada: moagem fina (DGM menor que $500 \mu \mathrm{m}$ ), moagem média (DGM entre $700 \mu \mathrm{m}$ e $1200 \mu \mathrm{m}$ ) e moagem grossa (DGM maior que $1200 \mu \mathrm{m}$ ) sobre o desempenho, a incidência de úlceras e a morfologia intestinal de suínos em crescimento. Para o desempenho, os animais alimentados com ração de moagem média apresentaram maior ganho de peso diário em comparação aos alimentados com moagem grossa (882 vs. $794 \mathrm{~g} /$ dia, respectivamente) e os alimentados com ração de moagem fina apresentaram maior consumo de ração em comparação aos alimentados com moagem média e grossa $(2,20 \mathrm{~kg} / \mathrm{dia} v s$. 2,09 e 2,10 $\mathrm{kg} / \mathrm{dia}$, respectivamente), desta forma, os autores concluíram que houve tendência de melhor conversão alimentar para os suínos alimentados com ração média. Quanto à presença de úlceras, houve baixa incidência para os suínos alimentados com moagem média e grossa, entretanto, foram registradas lesões no quadrilátero esofágico de todos os animais alimentados com ração de moagem fina. Menor espessura epitelial foi observada nos suínos submetidos à dieta de moagem grossa em relação à dieta fina, além disto, a dieta grossa também proporcionou maior distância entre a ponta das vilosidades até a base da tripa. Com base nestes resultados, concluiu-se que a dieta fina altera a morfologia intestinal de leitões 
desmamados e diminui a absorção de nutrientes e, com isto, a composição da mucina é afetada, prejudicando a saúde intestinal do animal.

Ayles et al. (1996) avaliaram a hipótese de cura de lesões gástricas em função do uso de partículas finas $(578 \mu \mathrm{m})$ e grossas $(937 \mu \mathrm{m})$ de milho e trigo nas dietas de suínos em crescimento. Segundo o estudo, quanto mais fina é a partícula, mais severa é a úlcera e menor é o desempenho dos suínos. Em outras palavras, os animais que foram alimentados continuamente com ração composta por partículas grossas apresentaram menores níveis de lesões do tipo úlcera, o que poderia ser um indicativo de efeito curativo.

A úlcera diminui o ganho médio diário de peso, aumenta o consumo de ração, piora a conversão alimentar e pode até causar a morte do animal, o que limita os resultados zootécnicos e econômicos do suinocultor (Rothuizen \& Meyer, 2004). Assim, a granulometria ideal contribui para o maior aproveitamento dos nutrientes, sem que haja o aparecimento de úlceras (Penz \& Magro, 1998), além de promover boa aceitação da ração, boa digestibilidade, máximo desempenho e preservar a saúde dos animais (Zanotto et al., 1998).

Kiarie \& Mills (2019) relataram que efeitos deletérios de partículas finas dependem do tipo de grão. Como exemplo, estudos encontraram maior score de queratose com grânulos de milho de $0,30 \mathrm{~mm}$ e sorgo grão duro de $0,90 \mathrm{~mm}$ e menor score para os mesmos tamanhos, porém com o uso de sorgo grão mole. Os autores afirmaram que há a possibilidade da moagem grossa contribuir para a saúde intestinal através da prevenção da proliferação bacteriana prejudicial, como a Salmonella e a E. coli, pela ação de ácidos graxos de cadeia curta.

\section{Efeitos da granulometria da dieta sobre a digestibilidade de nutrientes e a excreção de poluentes}

Bellaver (2001) afirmam que, em relação ao aproveitamento dos nutrientes pelo trato digestório, quanto menor o tamanho das partículas, maior o contato com o suco digestivo e maior sua digestão e absorção pelos animais. Para Bünzen et al. (2008), as alterações na digestibilidade estão mais relacionadas com a superfície de exposição às secreções digestivas do que com o tempo de passagem do bolo alimentar pelo trato gastrointestinal.

A digestibilidade dos grãos finos afeta a excreção de nitrogênio $(\mathrm{N})$ e fósforo $(\mathrm{P})$ pelos suínos. Oryschak et al. (2002) notaram que há poucos estudos sobre o efeito da redução do tamanho dos grãos sobre a digestibilidade e a excreção de $\mathrm{N}$ e $\mathrm{P}$, combinada com a suplementação enzimática. Assim, os autores avaliaram os efeitos do tamanho dos grãos de cevada e ervilha (DGM's de 400 e $700 \mu \mathrm{m}$ ) na dieta de suínos em crescimento sobre a taxa de excreção de $\mathrm{N}$ e P. Foi constatado que o tamanho dos grãos afetou a excreção de $\mathrm{P}$ nas fezes, mas não na urina e, além disto, a redução do tamanho dos grãos $(400 \mu \mathrm{m})$ diminuiu em $12 \%$ a excreção de P nas fezes e, portanto, aumentou em $15 \%$ sua digestibilidade e retenção.

Kim et al. (2002) relataram que o tamanho das partículas da ração afetou a taxa de excreção de N nas fezes e na urina de suínos na fase de creche. Desta forma, a diminuição da granulometria de 850 para $700 \mu \mathrm{m}$ aumentou em $13 \%$ a taxa de excreção de $\mathrm{N}$ na urina, enquanto que a redução de 700 para 400 $\mu$ m diminuiu em $18 \%$ a excreção de $\mathrm{N}$ fecal, reduziu em $7 \%$ a excreção total de $\mathrm{N}$, aumentou em $5 \%$ a digestibilidade e aumentou em $6 \%$ a taxa de retenção. Estes resultados comprovam a hipótese de que grãos finos melhoram a superfície de contato com enzimas digestivas e, desta forma, os autores sugerem que parte da redução da excreção de $\mathrm{N}$ fecal por diminuição do tamanho das partículas pode ter resultado em diminuição do contato com a ração, assim, reduzindo o $\mathrm{N}$ das fezes endógenas.

Lyu et al. (2020) avaliaram o efeito da granulometria do milho e dos lipídeos provenientes de duas fontes (óleo e gérmen de milho) na digestibilidade aparente total da energia, extrato etéreo e na digestibilidade total da dieta. Para ambas as fontes, foi relatada diminuição linear da digestibilidade total da energia bruta e da proteína bruta à medida que a granulometria aumentou de 441 para $768 \mu \mathrm{m}$. Considerando uma melhor digestibilidade encontrada para energia e nutrientes, o tamanho ideal de partícula de milho recomendado foi $618 \mu \mathrm{m}$.

Acosta et al. (2020) avaliaram a digestibilidade do milho para suínos em crescimento e terminação, considerando a moagem em moinho tipo martelo e tipo rolo. Foi verificado que a redução da 
granulometria de 700 para $300 \mu \mathrm{m}$, em moinho tipo rolo, aumentou a digestibilidade dos nutrientes, sem efeito para moinho tipo martelo. Isso pode ser devido às diferenças na distribuição, composição química e formato das partículas resultantes dos dois diferentes tipos de moinhos.

\section{Considerações gerais e recomendações de granulometria}

Em geral, o que se observa na literatura científica é que a diminuição do DGM é benéfica para o desempenho animal, pois diminui o consumo de ração e melhora a conversão alimentar, sem afetar o ganho de peso (Zanotto et al., 1999). Foi constatado também que a redução do DGM aumenta o valor energético do milho, melhorando o desempenho zootécnico. No entanto, a obtenção de grânulos menores demanda alto consumo de energia elétrica dos equipamentos, o que aumenta o custo de produção e pode estimular a formação de úlceras e hiperqueratose nos animais (Zanotto et al., 2016). Em complemento, Kiarie \& Mills (2019) relataram que moagens muito finas diminuem a capacidade de moagem dos moinhos, aumentam o problema de poeira nas fábricas e impactam negativamente a saúde intestinal dos animais. A Tabela 1 mostra as principais diferenças de recomendações de DGM encontradas na literatura e as variáveis impactadas.

Tabela 1. Recomendações de diâmetro geométrico médio (DGM) de diferentes tipos de grãos para rações de suínos e seus efeitos.

\begin{tabular}{|c|c|c|c|}
\hline Autor(es) & $\begin{array}{l}\text { Faixa recomendada } \\
(\mu \mathrm{m}) / \text { Tipo de grão }\end{array}$ & Áreas impactadas & Efeitos \\
\hline Healy et al. (1994) & $\begin{array}{c}300-900 \\
\text { Milho e Sorgo }\end{array}$ & Saúde animal & $\begin{array}{l}\text { Redução de ulceração e sem efeito na morfologia } \\
\text { intestinal. }\end{array}$ \\
\hline Wondra et al. (1995) & $\begin{array}{l}400-1000 \\
\text { Milho }\end{array}$ & Saúde animal & Redução de queratose. \\
\hline Zanotto et al. (1999) & $\begin{array}{l}500-650 \\
\text { Milho }\end{array}$ & $\begin{array}{c}\text { Saúde animal } \\
\text { Produção animal } \\
\text { Poluição ambiental } \\
\text { Custos de produção }\end{array}$ & $\begin{array}{l}\text { DGM's menores que } 500 \mu \mathrm{m} \text { estimulam o aparecimento } \\
\text { de úlcera e hiperqueratose. } \\
\text { DGM's maiores que } 650 \mu \mathrm{m} \text { diminuem o aproveitamento } \\
\text { dos suínos. } \\
\text { Produção de mais dejetos devido ao aumento de consumo } \\
\text { e aumento da poluição ambiental. } \\
\text { Economia de } 25 \mathrm{~kg} \text { de ração por suíno terminado. }\end{array}$ \\
\hline Mavromichalis et al. (2000) & $\begin{array}{l}400-1300 \\
\text { Trigo }\end{array}$ & Saúde animal & Redução de ulceração. \\
\hline \multirow[t]{2}{*}{$\underline{\text { Kim et al. (2002) }}$} & $\begin{array}{l}1.000 \\
\text { Milho }\end{array}$ & \multirow[t]{2}{*}{ Produção animal } & $\begin{array}{l}\text { Dietas complexas com milho a } 1.000 \mu \mathrm{m} \text { proporcionam } \\
\text { melhor desempenho do que dietas simples com milho a } \\
500 \text { um. }\end{array}$ \\
\hline & $\begin{array}{c}400 \\
\text { Milho }\end{array}$ & & $\begin{array}{l}\text { Diminuição da excreção de } \mathrm{N} \text { fecal e total, além de } \\
\text { aumento da digestibilidade e da taxa de retenção. }\end{array}$ \\
\hline$\underline{\text { Oryschak et al. }(2002)^{(}}$ & $\begin{array}{c}400 \\
\text { Cevada e ervilha }\end{array}$ & Produção animal & Aumento da digestibilidade e da retenção de P. \\
\hline \multirow[t]{2}{*}{ Morel \& Cottam (2007) } & $\begin{array}{c}700-800 \\
\text { Cevada } \\
430-1100\end{array}$ & \multirow[t]{2}{*}{ Produção animal } & $\begin{array}{l}\text { O desempenho na fase de crescimento em uma dieta com } \\
\text { base em cevada é otimizado com o uso de DGM } 700 \text { e } 800 \\
\mu \mathrm{m} .\end{array}$ \\
\hline & Cevada & & Redução de úlceras e sem efeito na morfologia intestinal. \\
\hline De Jong et al. (2012) & $\begin{array}{c}320 \\
\text { Milho }\end{array}$ & Produção animal & $\begin{array}{l}\text { Melhora conversão alimentar e diminuição dos custos de } \\
\text { alimentação por kg vivo. }\end{array}$ \\
\hline Zanotto et al. (2016) & $\begin{array}{l}480-600 \\
\text { Milho }\end{array}$ & - & $\begin{array}{l}\text { Adotou-se essa faixa como padrão, através da análise de } \\
\text { estudos anteriores. }\end{array}$ \\
\hline Longpré et al. 2016 & $\begin{array}{l}500-1250 \\
\text { Milho }\end{array}$ & Saúde animal & Redução de ulceração. \\
\hline Lyu et al.( 2020) & $\begin{array}{c}618 \\
\text { Milho }\end{array}$ & Produção animal & Melhor digestibilidade da energia e dos nutrientes. \\
\hline$\underline{\text { Acosta et al. (2020) }}$ & $\begin{array}{c}300 \\
\text { Milho }\end{array}$ & Produção animal & $\begin{array}{l}\text { Aumento da digestibilidade da energia e dos nutrientes, } \\
\text { para moagem em moinhos tipo rolo. }\end{array}$ \\
\hline
\end{tabular}

Fonte: Elaboração própria, com base em Kiarie \& Mills (2019).

\section{Considerações finais}

A partir dos diferentes resultados e recomendações de DGM na literatura científica verifica-se que a granulometria varia de acordo com o tipo de ingrediente e com a fase de produção dos suínos. Para a formulação de ração, é necessário, portanto, a escolha do tamanho correto dos grãos, considerando o 
que melhor se adequa aos objetivos relacionados ao desempenho e saúde dos animais, à digestibilidade dos nutrientes, ao potencial de excreção de poluentes e ao custo de produção.

\section{Referências bibliográficas}

Acosta, J. A., Petry, A. L., Gould, S. A., Jones, C. K., Stark, C. R., Fahrenholz, A. C., \& Patience, J. F. (2020). Enhancing digestibility of corn fed to pigs at two stages of growth through management of particle size using a hammermill or a roller mill. Translational Animal Science, 4(1), 10-21. https://doi.org/10.1093/tas/txz146.

Amornthewaphat, N., Behnke, K. C., \& Hancock, J. D. (1998). Effects of particle size and mixing time on uniformity and segregation in pig diets. Kansas Agricultural Experiment Station Research Reports, 10, 261-263. https://doi.org/10.4148/2378-5977.6558.

ANUALPEC. (2020). Anuário da Pecuária Brasileira (20th ed., Vol. 1). Instituto FNP.

Ayles, H. L., Friendship, R. M., \& Ball, R. O. (1996). Effect of dietary particle size on gastric ulcers, assessed by endoscopic examination, and relationship between ulcer severity and growth performance of individually fed pigs. Journal of Swine Health and Production, 4(5), 211-216.

Bellaver, C. (2001). Ingredientes de origem animal destinados à fabricação de rações. Simpósio Sobre Ingredientes Na Alimentação Animal, 1(1), 1-23.

Bünzen, S., Salguero, S., Albino, L. F. T., \& Rostagno, H. S. (2008). Recentes avanços na nutrição de suínos. Simpósio Brasil Sul de Suinocultura, 1, 1-129.

De Jong, J. A., Tokach, M. D., McKinney, L. J., DeRouchey, J. M., Goodband, R. D., Nelssen, J. L., \& Dritz, S. S. (2012). Effects of corn particle size, complete diet grinding, and diet form on finishing pig growth performance, caloric efficiency, carcass characteristics, and economics. Agricultural Experiment Station and Cooperative Extension Service, 10, 316-324. https://doi.org/10.4148/23785977.7080.

FAPRI. (2020). Food and Agricultural Policy Research Institute (W. A. O. Database (ed.)). Food and Agricultural Policy Research Institute; Iowa State University and University of Missouri-Columbia. http://www.fapri.iastate.edu/tools/outlook.aspx

Healy, B. J., Hancock, J. D., Kennedy, G. A., Bramel-Cox, P. J., Behnke, K. C., \& Hines, R. H. (1994). Optimum particle size of corn and hard and soft sorghum for nursery pigs. Journal of Animal Science, 72(9), 2227-2236.

Hedde, R. D., Lindsey, T. O., Parish, R. C., Daniels, H. D., Morgenthien, E. A., \& Lewis, H. B. (1985). Effect of diet particle size and feeding of $\mathrm{H} 2$-receptor antagonists on gastric ulcers in swine. Journal of Animal Science, 61(1), 179-186. https://doi.org/10.2527/jas1985.611179x.

Kiarie, E. G., \& Mills, A. (2019). Role of feed processing on gut health and function in pigs and poultry: conundrum of optimal particle size and hydrothermal regimens. Frontiers in Veterinary Science, 6, 19. https://doi.org/10.3389/fvets.2019.00019.

Kim, I. H., Hancock, J. D., Hong, J. W., Cabrera, M. R., Hines, R. H., \& Behnke, K. C. (2002). Corn particle size affects nutritional value of simple and complex diets for nursery pigs and broiler chicks. Asian-Australasian Journal of Animal Sciences, 15(6), 872-877. https://doi.org/10.5713/ajas.2002.872.

Longpré J, Fairbrother JM, Fravalo P, Arsenault J, LeBel P, Laplante B. (2016). Impact of mash feeding versus pellets on propionic/butyric acid levels and on total Escherichia coli load in the gastrointestinal tract of growing pigs1. J Anim Sci. (2016) 94:1053-63. doi: 10.2527/jas.2015-96171.

Lyu, Z., Wang, L., Wu, Y., \& Huang, C. (2020). Effects of particle size and lipid form of corn on energy and nutrient digestibility in diets for growing pigs. Asian-Australasian Journal of Animal Sciences, 33(2), 286-293. https://doi.org/10.5713/ajas.19.0196.

Martins, F. M., Santos Filho, J. I., \& Talamini, D. J. (2019). Conjuntura econômica da suinocultura brasileira. In Embrapa Suínos e Aves-Artigo de divulgação na mídia (INFOTECA-E) (p. 291). Anuário 2020 da Suinocultura Industrial, Itu, ed. 291, n. 6, ano 42, p. 14.

Mavromichalis, I., Hancock, J. D., Senne, B. W., Gugle, T. L., Kennedy, G. A., Hines, R. H., \& Wyatt, C. L. (2000). Enzyme supplementation and particle size of wheat in diets for nursery and finishing 
pigs. Journal of Animal Science, 78(12), 3086-3095. https://doi.org/10.2527/2000.78123086x.

Morel, P. C., \& Cottam, Y. H. (2007). Effects of particle size of barley on intestinal morphology, growth performance and nutrient digestibility in pigs. Asian-Australasian Journal of Animal Sciences, 20(11), 1738-1745. https://doi.org/10.5713/ajas.2007.1738.

Oliveira, L. C., Medeiros, C. M. O., Silva, I. N. G., Monteiro, A. J., Leite, C. A. L., \& Carvalho, C. B. M. (2005). Susceptibilidade a antimicrobianos de bactérias isoladas de otite externa em cães. Arquivo Brasileiro de Medicina Veterinária e Zootecnia, 57(3), 405-408.

Oryschak, M. A., Simmins, P. H., \& Zijlstra, R. T. (2002). Effect of dietary particle size and carbohydrase and/or phytase supplementation on nitrogen and phosphorus excretion of grower pigs. Canadian Journal of Animal Science, 82(4), 533-540. https://doi.org/10.4141/A02-017.

Pandorfi, H., Almeida, G. L. P., \& Guiselini, C. (2012). Zootecnia de precisão: princípios básicos e atualidades na suinocultura. Revista Brasileira de Saúde e Produção Animal, 13(2), 558-568.

Penz, A. M., \& Magro, N. (1998). Granulometria de rações: Aspectos fisiológicos. Simpósio Sobre Granulometria de Ingredientes e Rações Para Suínos e Aves., 1, 74.

Rothuizen, J., \& Meyer, H. P. (2004). Anamnese, exame físico e sinais da doença hepática. In S. J. Ettinger \& A. Feldman (Eds.), Tratado de Medicina Interna Veterinária (Vol. 2, pp. 1342-1347). Manole.

Silva, M. L. F., Fialho, E. T., Lima, J. A. F., Sousa, R. V., Murgas, L. D. S., \& Oliveira, V. (2006). Formulação de rações para suínos em terminação utilizando valores de digestibilidade ileal verdadeira de aminoácidos. Boletim de Indústria Animal, 63(1), 19-26.

Talamini, D. J. D., \& Santos Filho, J. I. (2017). Atualidades da suinocultura brasileira. Embrapa Suínos e Aves, 279, 16-23.

Wondra, K. J., Hancock, J. D., Behnke, K. C., Hines, R. H., \& Stark, C. R. (1995). Effects of particle size and pelleting on growth performance, nutrient digestibility, and stomach morphology in finishing pigs. Journal of Animal Science, 73(3), 757-763. https://doi.org/10.2527/1995.7392564x.

Zanotto, D L, Cunha Júnior, A., Ludke, J. V, Ccoldebella, A., \& Bertol, T. M. (2016). Método rápido para análise da granulometria do milho em fábrica de ração. Embrapa Suínos e Aves-Circular Técnica, 538.

Zanotto, D L, Guidoni, A. L., \& Pieniz, L. C. (1999). Granulometria do milho em rações para engorda de suínos. Embrapa Suínos e Aves-Recomendação, 244, $1=2$.

Zanotto, Dirceu L, Brum, P. A. R., \& Guidoni, A. L. (1998). Granulometria do milho em rações para frangos de corte. Embrapa Suínos e Aves-Comunicado Técnico, 8, 43.

Zanotto, Dirceu Luis, \& Bellaver, C. (1996). Método de determinação da granulometria de ingredientes para uso em rações de suínos e aves. EMBRAPA, 215, 1-5.

\section{Histórico do artigo:}

Recebido: 19 de junho, 2020.

Aprovado: 1 de agosto, 2020.

Disponível online: 9 novembro, 2020.
Licenciamento: Este artigoé publicado na modalidade Acesso Aberto sob a licença Creative Commons Atribuição 4.0 (CC-BY 4.0), a qual permite uso irrestrito, distribuição, reprodução em qualquer meio, desde que $o$ autor e a fonte sejam devidamente creditados 